DOI: https://doi.org/10.47405/mjssh.v6i9.991

\begin{tabular}{|c|c|}
\hline & Malaysian Journal of Social Sciences and Humanities (MJSSH) \\
\hline Malaysian Journal of & Volume 6, Issue 9, September 2021 \\
\hline (MJ-SSH) & e-ISSN : 2504-8562 \\
\hline & $\begin{array}{l}\text { Journal home page: } \\
\text { www.msocialsciences.com }\end{array}$ \\
\hline
\end{tabular}

\title{
Penemuan Gendang Gangsa Timbang Dayang di Pulau Banggi, Sabah
}

\author{
Nordiana Nasuha Molinka1, Baszley Bee Basrah Bee ${ }^{1}$, Maureen De Silva ${ }^{1}$ \\ 1 Fakulti Sains Sosial dan Kemanusiaan, Universiti Malaysia Sabah (UMS)
}

Correspondence: Nordiana Nasuha Molinka (dianamolinka@gmail.com)

\begin{abstract}
Abstrak
Penemuan gendang gangsa Timbang Dayang (GGTD) telah mewajarkan semula interpretasi sejarah keberadaan gendang gangsa di Malaysia khususnya di Sabah. Sehingga kini, koleksi gendang gangsa di Malaysia adalah sejumlah 22 buah gendang yang masih banyak kelompangan atau ruang kajian untuk dikongsikan dengan umum. Koleksi tersebut melibatkan penemuan secara tidak sengaja, koleksi sedia ada di istana, muzium dan orang perseorangan. Manakala GGTD pula merupakan gendang gangsa tunggal yang ditemui di timur Malaysia dan yang ketiga di Borneo selepas Sambas I dan Sambas II. Artifak GGTD berkondisi 70\% lengkap-rapuh dengan kesan patina dan kotoran tanah yang masih belum dibersihkan menyukarkan proses analisis fizikal. Namun demikian, proses pendokumentasian harus dilakukan sebagai usaha menyelamatkan data arkeologi pada gendang sebelum keadaan tahap kemerosotan bertambah serius. Sehubungan dengan itu, fokus perbincangan adalah menjelaskan bagaimana GGTD berada di bukit Timbang Dayang, pulau Banggi, Kudat. Diharapkan dengan adanya kajian ini dapat memberikan interpretasi terkini dan meletakkannya setara dengan kajian gendang gangsa yang lain di Malaysia dan Asia Tenggara umumnya.
\end{abstract}

Kata kunci: gendang gangsa, pulau Banggi, perdagangan, teluk Marudu, zaman gangsa

\section{The Discovery of Gendang Gangsa Timbang Dayang di Pulau Banggi, Sabah}

\begin{abstract}
The discovery of Gendang Gangsa Timbang Dayang (GGTD) has a new impact on bronze drums studies in Malaysia, especially in Sabah. The collection of bronze drums in Malaysia is 22 drums including five drums that not yet classified. The collection involves accidental discovery and the collection from the Terangganu palace and private collection, GGTD is the only one bronze drum found in East Malaysia and the third in Borneo after Sambas I and Sambas II. GGTD artifact is fragile as $70 \%$ of it is damages caoused by patina and stubborn dirt which made it difficult to conduct a through physical analysis However, a documentation of the drum is requires to extract importan data from the drum before the physical condition deteriorated. Also, this study is vital to provide a brief discussion on how the GGTD artifact happendes to be in Bukit Timbang Dayang, Pulau Banggi, Kudat, Sabah. Hopefullu, this study can provide the latest information about GGTD and give some new data to bronze Age in Sabah.
\end{abstract}

Keywords: Bronze drum, Banggi Island, trade, Marudu Bay, Bronze Age 


\section{Pengenalan}

Artifak gendang gangsa yang dikenali sebagai gendang gangsa Timbang Dayang GGTD) ditemui di dalam gua yang sempit yang terletak di sebuah bukit yang dikenali sebagai bukit Timbang Dayang di bahagian psisir pantai timur Pulau Banggi, Kudat. Secara harfiahnya, GGTD merupakan pecahan artifak yang rapuh dan mengalami kemerosotan fizikal akibat pengoksidaan. Walau bagaimanapun, pecahan artifak tersebut masih mampu mewakili dan memberikan petunjuk kepada rupa bentuk sebenar gendang gangsa. Kini, pecahan artifak tersebut dipamerkan untuk tatapan umum di Muzium Sabah.

\section{Penemuan dan Penyebaran GGTD}

GGTD (Foto 1) dijumpai secara tidak sengaja oleh penduduk kampung dan diserahkan kepada pihak Muzium Sabah ketika aktiviti survei tapak arkeologi di kawasan Bukit Timbang Dayang dilakukan sekitar tahun 1994. Memandangkan tapak arkeologi di bukit ini merupakan tapak terganggu kerana pernah diselongkar oleh para pemburu harta karun (antiquarian), maka banyak artifak lain yang berasosiasi dengan gendang gangsa tersebut sekiranya diketemukan secara in-situ kerana kawasannya yang masih belum dibangunkan.

Foto 1: Timpanum GGTD yang dipamerkan di ruangan pameran Muzium Sabah

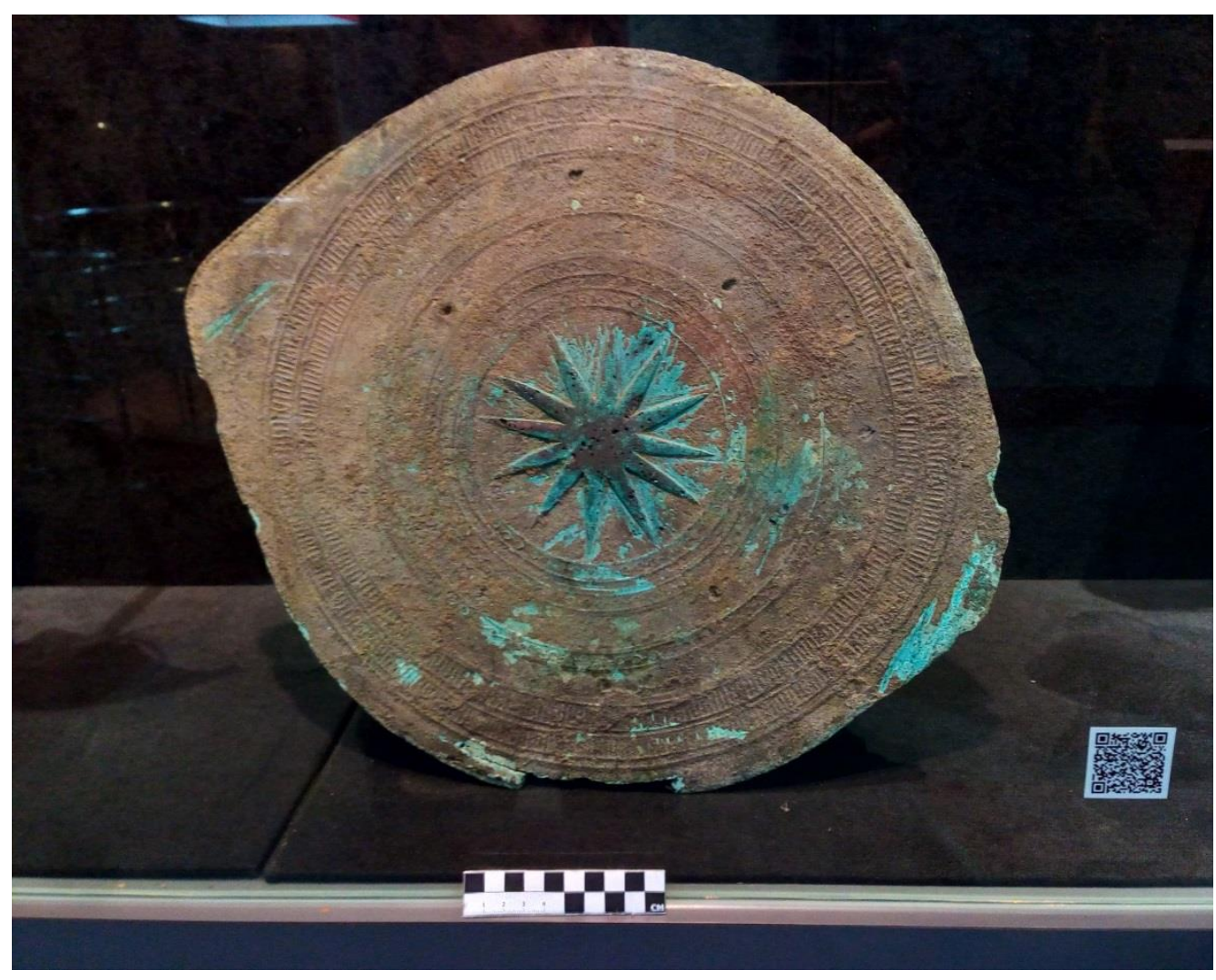

Sumber: Unit Arkeologi Muzium Sabah

Satu ekskavasi penyelamatan telah dilakukan oleh Unit Arkeologi, Muzium Sabah pada 12-15 Ogos 1994 dan menemukan tembikar, pecahan tembikar dan manik pelbagai jenis. Keadaan gua yang sempit (Foto 2) dan sangat gelap adalah halangan utama semasa kajian lapangan dilakukan (ARK P1/08). 
DOI: https://doi.org/10.47405/mjssh.v6i9.991

Foto 2: Gua sempit yang terdapat di Bukit Timbang Dayang, Pulau Banggi

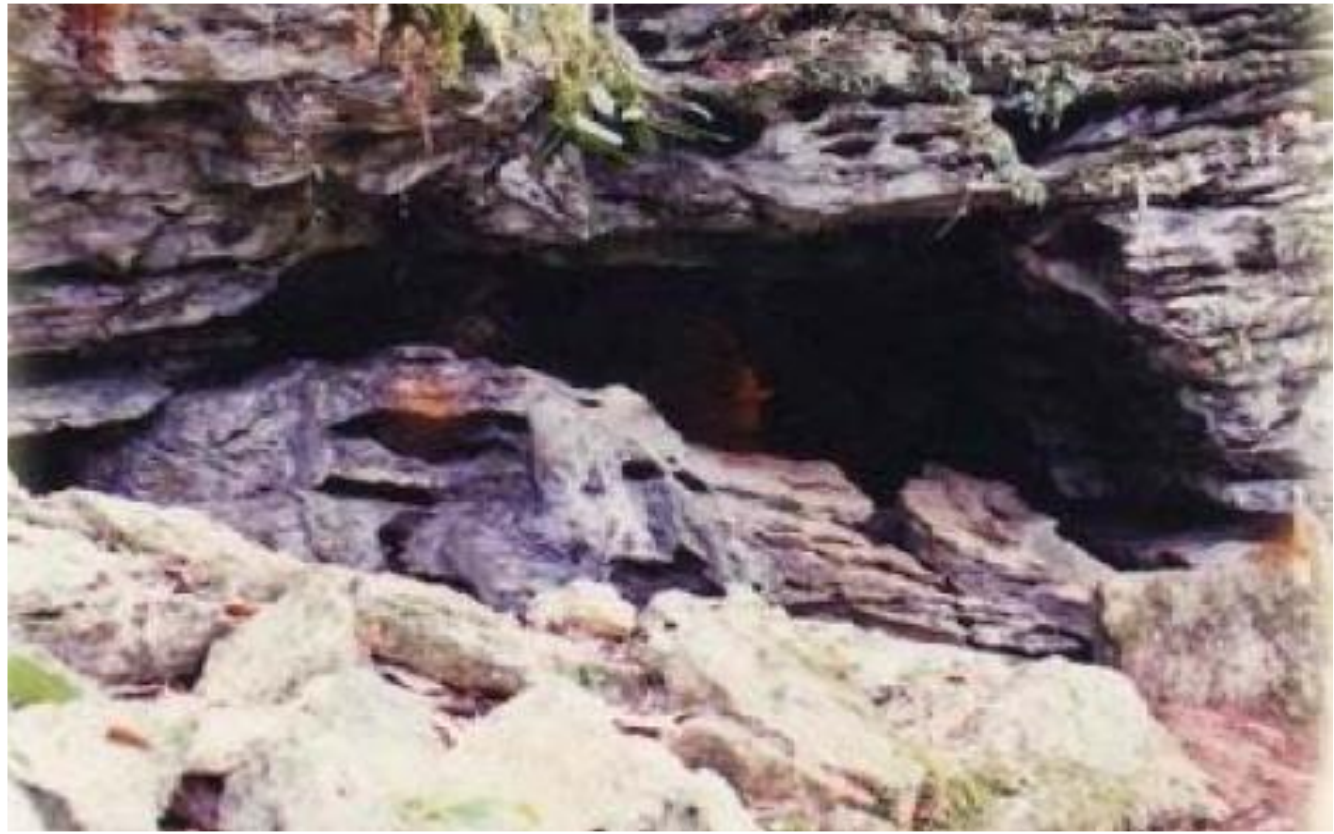

Sumber: Unit Arkeologi Muzium Sabah

Penemuan artifak GGTD menjadi petunjuk bahawa kawasan tersebut pernah dilawati oleh orang dari luar Pulau Bangi. Seperti yang diketahui, kebudayaan gendang gangsa adalah budaya masyarakat di kawasan tanah besar Asia seperti utara Vietnam dan selatan China. Keberadaan artifak GGTD di utara Borneo menunjukkan terdapat faktor penarik yang menyebabkan masyarakat luar berkunjung ke kawasan Teluk Marudu. Antara faktor berkenaan adalah kedudukan pulau Banggi yang berada di kawasan perairan yang merupakan pintu masuk Teluk Marudu serta dan terletak di laluan perdagangan kedua iaitu dari tanah besar Asia ke kawasan Borneo menuju ke kepulauan Maluku (Peta 1).

Peta 1: Laluan Perdagangan di Asia Tenggara dan penyebaran Gendang Gangsa di Asia Tenggara

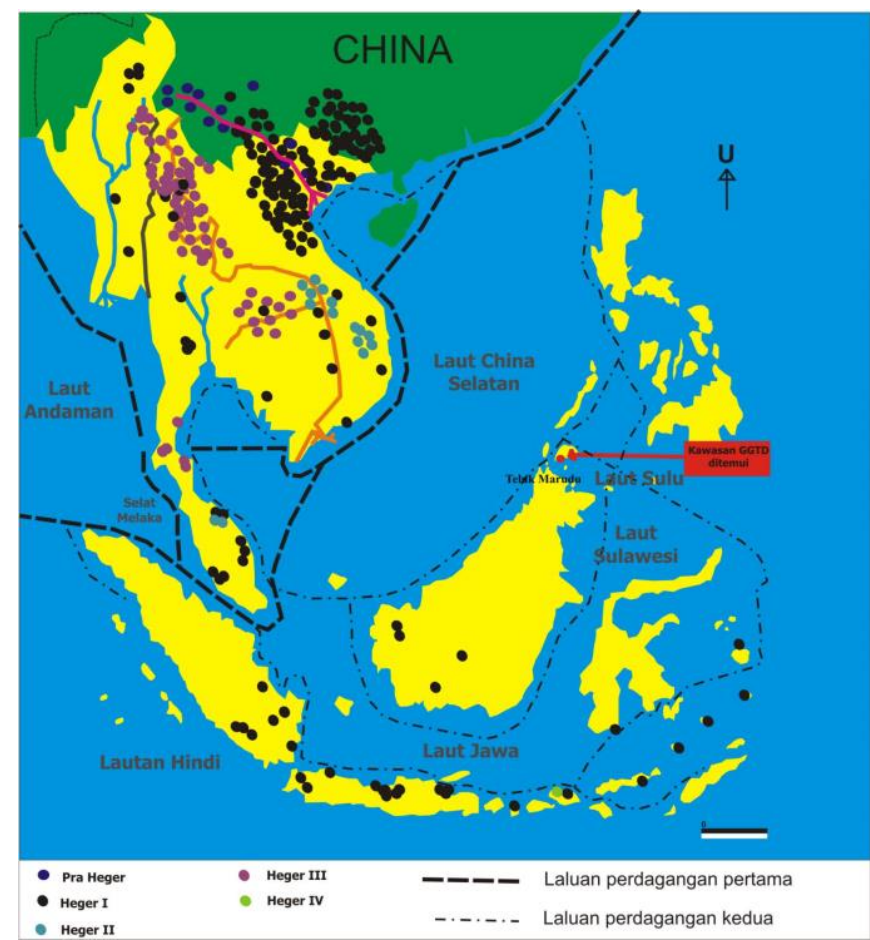

Sumber: Dipetik dan diubahsuai daripada Miller (2010: 46) dan Calo (2007:122-130) 
Perkara ini turut disokong dengan fakta bahawa kawasan perairan Kudat terutamanya terusan Tanjung Simpang Mengayau merupakan antara laluan kapal purba dan antara lokasi perdagangan maritim terawal di sekitar pantai barat utara Borneo (Baszley \& Bala, 2007; Baszley, Bala \& Sherman, 2005). Di samping itu, terdapat juga beberapa tempat persinggahan dan pelabuhan kecil sepanjang semenanjung Kudat dan semenanjung Pitas seperti Sungai Bintasan, sungai Langkon, sungai Bengkoka dan Malubang (Baszley, 2004:1-13; Manzes, 2017:65-74). Penemuan artifak dan tapak kapal karam di sepanjang semenanjung Kudat membuktikan kawasan tersebut aktif dengan aktiviti perdagangan maritim dan wujud hubungan dengan China terutamanya dengan Dinasti Song (960-1127 Masihi) (Baszley, Bala \& Sherman, 2005). Kemasyhuran Teluk Marudu telah lama diketahui oleh masyarakat luar yang dibuktikan dengan catatan perjalanan Caspaar Viegas (1537), (Manzes, 2019:41) dan Isaac Tirion (1745-1760) yang memetakan Manado (merujuk kepada Marudu) dalam peta pelayaran beliau. Kemudiannya, Alexander Dalrymple memperincikan semula kedudukan Teluk Marudu dalam peta antara tahun 1770-1779 (Manzes, 2017:65-74).

Selain terkenal sebagai pusat perdagangan hamba abdi di kawasan pantai barat Borneo (Sajok, 2017: 20-28) Teluk Marudu juga terkenal dengan hasil laut seperti gamat, trepang, mutiara dan kura-kura (British North Borneo Chartered Company, 1899:21) serta merupakan antara pengeluar hasil hutan seperti rotan (Drabble, 2000:20), damar dan kapur barus di utara Borneo. Teluk Marudu umpama kawasan 'rehat dan rawat' kepada para pelayar dan pedagang. Earl (1971) pernah mencatatkan bahawa suasana di Teluk Marudu adalah sangat baik, aman damai dan selamat untuk dilawati (Earl, 1971:322323). Kesemua gugusan pulau yang terletak di kawasan pesisir pantai utara Borneo iaitu sebanyak 229 pulau diletakkan dalam gugusan pulau I de Santa Maria (Island of Saint Mary) termasuklah Pulau Banggi dan Pulau Balambangan. Kedua-dua pulau tersebut pernah menjadi perhatian Alexander Dalrymple sehingga membawa kepada kertas cadangan pembukaan Felicia Proper untuk tujuan monopoli perdagangan EEIC di kawasan tersebut. Kedudukannya yang terletak tepat di kawasan pintu masuk dan keluar ke kawasan teluk Marudu memberikan keistimewaan yang lebih malahan merupakan penanda atau landmark kepada pedagang terutamanya yang melalui laluan perdagangan Laut China Selatan - Laut Sulu - Kepulauan Maluku (Baszley, 2004:1-13).

Seiring dengan kepesatan perdagangan, penyebaran gendang gangsa di Asia Tenggara juga berlaku melalui laluan perdagangan dari tanah besar Asia ke kepulauan Asia Tenggara (Calo, 2012:11-117; Calo, 2007:75) Walau bagaimanapun, gendang gangsa tidak dipasarkan seperti barangan lain (Adnan, Yunus \& Zuliskandar, 2011:1-13) dalam bentuk pasaran terbuka tetapi secara pasaran khusus dalam kalangan kelas bangsawan atau khusus iaitu berdasarkan permintaan tempahan atau pre-order. Pasaran khusus yang tertutup dan tidak meluas adalah penting dalam menjaga kualiti, fungsi dan aura gendang itu sendiri.

\section{Kepentingan Tapak dan Fungsi GGTD}

Jika diperhalusi perkaitan pulau Banggi dan teluk Marudu yang terletak di laluan perdagangan, jelas menunjukkan bahawa kawasan sekitar tapak arkeologi Timbang Dayang berperanan sebagai kawasan persinggahan atau tempat berlindung sementara menanti peralihan angin monsun atau sebelum memasuki Teluk Marudu bagi mengelakkan kesesakan dan terdedah kepada bahaya serangan lanun. Selain itu, kawasan tersebut juga sesuai sebagai kawasan pelabuhan bagi membaiki kapal yang rosak (Adnan, Yunus \& Zuliskandar, 2011:1-13). Kedudukan tapak arkeologi Bukit Timbang Dayang terletak di bahagian belakang Pulau Banggi iaitu menghadap ke arah Pulau Malawali serta tersembunyi daripada kesibukan yang berlaku di kawasan tumpuan perdagangan memberikan kelebihan kepada kawasan pesisir bukit tersebut.

Tambahan pula, kawasan tepi pantai tersebut mempunyai gua yang sesuai digunakan sebagai penyimpanan barangan dan persembunyian. Berdasarkan hasil kajian ekskavasi penyelamatan, tapak gua berkenaan juga berfungsi sebagai tapak pengebumian yang mewakili zaman Gangsa berusia lebih kurang 2,000-1,500 tahun dahulu berdasarkan artifak yang ditemui (APK P1/08). 
Oleh yang demikian, jelaslah bahawa kawasan sekitar tapak dan Pulau Banggi secara amnya telah diketahui kepada para pedagang dan pelayar yang berlabuh di sekitar Teluk Marudu. Kemungkinan besar tapak arkeologi berkenaan pada mulanya berperanan sebagai tempat persembunyian dan gudang penyimpanan barangan sahaja, namun setelah melewati masa yang panjang tapak gua sempit tersebut dijadikan sebagai tempat pengebumian oleh pedagang atau pelayar yang mati semasa berada di gua tersebut. Atau, menjadi lokasi pilihan yang sesuai sebagai tempat pengebumian yang terselindung dari penyelongkaran harta karun si mati.

Merujuk kepada artifak ditemui, si mati merupakan golongan yang berpengaruh dan mempunyai status sosial yang tinggi serta pemilik kepada gendang gangsa berkenaan. Berdasarkan dekorasi dan motif gendang, GGTD hanyalah gendang asas yang tidak ada kaitan dengan pelayaran. Ia juga milik perseorangan dan bertujuan sebagai azimat perlindungan diri atau sebagai menunjukkan status sosial si pemilik. Nilai sebuah gendang gangsa adalah terlalu tinggi iaitu hampir setara dengan gading gajah kerana gajah tidak terdapat di Kepulauan Maluku, Indonesia (Andaya, 2016:66-89.). Walau pun tapak tersebut dianggap sebagai tapak pengebumian zaman Gangsa kerana keberadaan GGTD, namun rangka atau tulang manusia tidak berjaya ditemui. Perkara ini menyebabkan interpretasi tersebut masih terbuka untuk dicabar kekuatannya. Pereputan rangka manusia secara total tanpa meninggalkan sebarang sisa tulang adalah suatu yang perlu dibuktikan secara saintifik. Manakala pandangan yang menganggap para pemburu harta karun telah membuang, merosakkan atau mencampakkan rangka manusia ke laut merupakan sekadar anggapan yang lemah. Nilai gendang gangsa yang tinggi tidak memungkinkannya ditinggalkan begitu sahaja oleh para penyelongkar kecuali gendang telah mengalami kerosakan sebelum diketemui oleh mereka. Justeru itu, kajian lanjutan diperlukan pada masa hadapan bagi merungkaikan dan memperkukuhkan interpretasi kajian.

\section{Kesimpulan}

Maka, jelaslah bahawa penemuan GGTD amat penting untuk dikaji secara saintifik dan perlu pendokumentasian yang lebih lengkap dalam usaha mengilap sumbangannya dalam pengkajian gendang gangsa di Asia Tenggara. Kehadirannya di Pulau Banggi menunjukkan kawasan tersebut pernah dikunjungi oleh orang luar atau sudah mempunyai hubungan dengan masyarakat luar. Meskipun demikian, budaya gendang gangsa tidak berasimilasi dengan budaya tempatan di tanah besar utara Borneo kerana tiadanya penemuan sedemikian. GGTD adalah bukti sejarah maritim utara Borneo tetapi di luar konteks kebudayaan masyarakat tempatannya.

\section{Rujukan}

Adnan Jusoh \& Yunus Sauman @ Sabin. (2019). Motif hiasan tiga (3) buah gendang gangsa di Muzium Marang, Perak. Seminar Arkeologi Kebangsaan 4, 76-90.

Adnan Jusoh, Yunus Sauman \& Zuliskandar Ramli. (2011). Penemuan gendang gangsa di Terengganu dan hubungkaitnya dengan aktiviti perdagangan, Posiding Seminar Arkeologi Terengganu 2011: $1-13$.

Andaya, Leondard Y. (2016). The Social Value of Elephant Tusks and Bronze Drums among certain Societies in Eastern Indonesia. Bijdragen tot de Taal-, Land- en Volkenkunde, 172, 66-89.

ARK P1/08- Timbang Dayang (Fail Muzium Sabah).

Baszley Bee \& Bilcher Bala. (2007). Sejarah Penempatan dan Perdagangan Awal di Utara Sabah Abad ke-10 Hingga ke-19. Laporan Akhir Penyelidikan FRGS. Universiti Malaysia Sabah.

Baszley Bee, Bilcher Bala \& Mohd. Sherman Sauffi. (2005). Arkeologi Bawah Air di Perairan Tanjung Simpang Mengayau Kudat, Sabah, 30 Julai-21 Ogos 2004. Laporan Akhir Penyelidikan. Jabatan Muzium dan Antikuti.

British North Borneo Chartered Company (1899). Views Of British North Borneo: With a brief history of the colony, compiled from official records and other sources of information of an authentic nature, with trade returns, \& C., showing the progress and development of the Chartered Company's territory to the latest date. Cornell University Library: W. Brown \& Co. Ltd. 
DOI: https://doi.org/10.47405/mjssh.v6i9.991

Calo, A. (2007). Transitions of a feathered world:The distribution of bronze drums in early Southeast Asia, Ph.D Thesis. SOAS University of London.

Calo, A. (2012). The distribution of bronze drums in early Southeast Asia: Trade routes and cultural spheres. Oxford: Archaeopress.

Drabble, J. (2000). An Economic History of Malaysia, c. 1800-1900: The Transition to Modern Economic Growth. New York: Springer.

Earl, G.W. (1971). The Eastern Seas. Oxford: University Press, Oxford.

Kempers, A.J.B. (1988). The Kettledrums in Southeast Asia: A Bronze Age world and its Aftermath. Rotterdam: A. A. Balkema Publisher.

Manzes, Any Farina. (2017). Teluk Marudu berdasarkan catatan peta Alexander Dalrymple. Jurnal Borneo Arkhailogia, 1(1), 65-74.

Manzes, Any Farina. (2018). Warisan Kebudayaan Ketara Dan Tidak Ketara Di Teluk Marudu Sebelum Tahun 1881. Tesis Sarjana. Universiti Malaysia Sabah.

Miller, Van Dennis. (2010). The Kettledrums of Insular Southeast Asia Protohistoric Distribution and Localization. Master Thesis. Leidein University.

Mohd Yusof Abdullah. (1993). Gendang Dong Son di Muzium Negeri Terengganu: Satu Catatan. Jurnal Arkeologi Malaysia, 6, 51-62.

Sajok, Aping. (2017). Perhambaan tradisional di Borneo Utara zaman kesultanan Sulu dan Brunei. Sains Insani, 2(2), 20-28. 